\title{
PALABRAS PRELIMINARES
}

A 40 años del primer número de nuestra Revista Estudios Pedagógicos, la convicción de las y los colegas que la fundaron, encabezados por el Dr. Erwin Haverbeck Ojeda, resultó augural: la necesidad de investigación educativa se hacía entonces y hoy, más que nunca, una labor urgente. La publicación se fundó en tiempos aciagos y argumentada no sólo por el déficit de saberes rigurosos y sistemáticos en el campo educacional, sino también para el mejor provecho decisional de las autoridades políticas del momento. De esta forma, la publicación sobrevivió a los varios intentos de desmantelamiento de las disciplinas humanistas y científico sociales al interior de las universidades, y persistió durante años, con propiedad y seriedad, como una de las escasas, sino la única, revistas científicas chilenas en su área. Hoy, tal como lo imaginaban los colegas que le dieron vida, Estudios Pedagógicos se encuentra renovada y vivificada, abierta a todas las perspectivas teóricas y epistemológicas, con un enorme caudal de colaboraciones nacionales e internacionales. Todo ello, preciso es destacarlo, gracias al liderazgo de una nueva generación de investigadoras e investigadores educacionales de la Facultad de Filosofía y Humanidades, que han sabido dar continuidad a uno de nuestros mejores y más representativos frutos.

\section{Yanko González C.}

DECANO, Facultad de Filosofía y Humanidades. 
